\title{
Quantification and potential role of ocean nutrient loading to Boston Harbor, Massachusetts, USA
}

\author{
John R. Kelly* \\ 3 Willow Lane, Rye, New Hampshire 03870, USA
}

\begin{abstract}
While tidal flushing helps export most of the nitrogen added to Boston Harbor (MA, USA) from land sources (>8000 mmol N m${ }^{-2} \mathrm{yr}^{-1} ; 90 \%$ in sewage effluent) to the offshore waters of Massachusetts Bay, the tidal inflow also brings material into the Harbor. For Boston Harbor and many other coastal embayments, tidal inputs must be quantified if we are to develop complete nutrient budgets. This study quantifies tidal input of nutrients and suspended solids (i.e. 'ocean loading') and predicts the future role of ocean loading after sewage effluent discharge is diverted away from the Harbor to a location about $15 \mathrm{~km}$ into the Bay. Ocean loading is determined by simple box modeling using data sets available for the 1994 annual cycle. Critical data for modeling include a series of surveys on which high-resolution data for salinity and turbidity were collected using in situ sensors housed in a towed instrument package (i.e. a 'towfish'); surveys covered 2 transects in and out of the 2 Harbor inlets which regulate tidal exchange. Study results show that ocean loading dominates the input-output budgets of nutrients and suspended solids, generally providing more than twice the loading from present land sources. Results further suggest that, although the absolute values of ocean loading will decrease after effluent diversion, the relative contribution of the ocean to the Harbor budget will increase. Predictive modeling suggests that total nitrogen concentrations will decrease about $20 \%$ and dissolved inorganic concentrations will decrease about $50 \%$ from present levels; these predicted decreases are smaller than one would calculate if the ocean loading term of budgets were neglected. Ocean loading thus will have a role in the nature of Harbor recovery from the planned sewage diversion.
\end{abstract}

KEY WORDS: Estuary nutrient budgets - Ocean loading Boston Harbor

\section{INTRODUCTION}

One component of the total nutrient input to estuarine systems is the input from the sea. This input, or 'ocean loading,' arises from exchange and mixing of offshore waters with shallow coastal embayments and estuaries. Interaction of inshore and offshore waters is complex, involving freshwater flows, tides, winds, and various coastal circulation processes. Even in wellstudied systems, ocean loading has usually not been estimated directly and, consequently, nutrient budgets generally are not fully 'closed' in the sense of having contemporaneous information to assess the balance

- Present address: U.S. EPA, Mid-Continent Ecology Division, 6201 Congdon Blvd, Duluth. Minnesota 55804-2595, USA E-mail: kelly.johnr@epa.gov between inputs, outputs, and sinks. At best, the net export of material flowing from watersheds has been established by the difference between 'land loading' and internal sinks within an estuary (e.g. Nixon et al. 1995).

Boston Harbor is a moderately large coastal embayment $\left(\sim 103 \mathrm{~km}^{2}\right)$ in the New England region of the northeastern United States. Tidal ranges are large and tidal flushing is an important process which structures water quality and the nutrient budget (cf. Signell \& Butman 1992, Kelly 1997a). In principle, in addition to providing a flushing mechanism, tidal exchange and mixing must be significant in providing an ocean-side nutrient input to many New England systems, especially those with low freshwater inputs (Kelly 1997b). For example, Nixon (1997) argued that ocean loading was more important to Narragansett Bay during presettlement times than at present. 


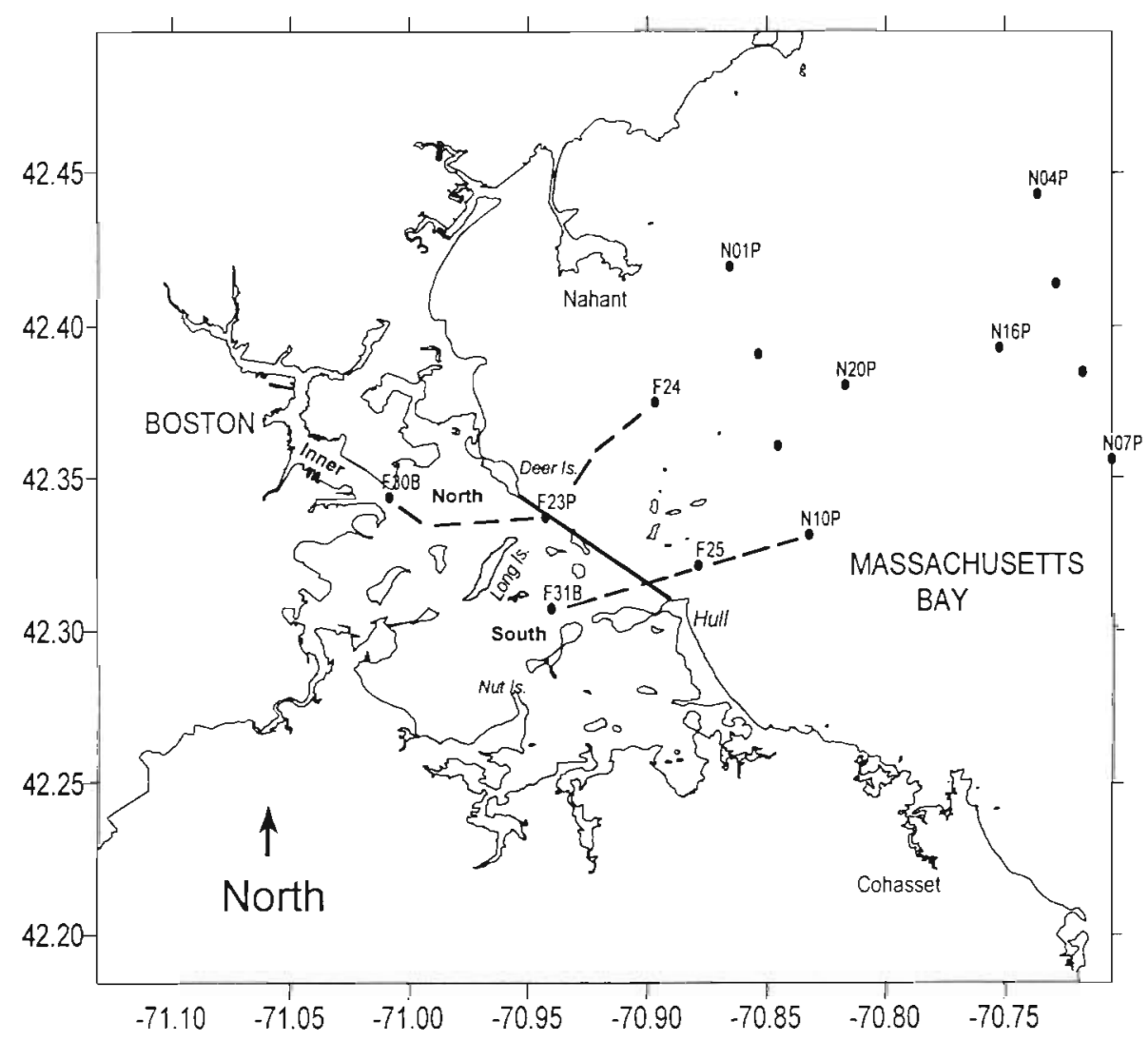

Fig. 1. The study area $\left({ }^{\circ} \mathrm{N}\right.$ latitude and ${ }^{\circ} \mathrm{W}$ longitude) in Boston Harbor and western Massachusetts Bay. The boundary between the Harbor and the Bay is defined by the solid line from Deer Island to Hull; combined with the dashed lines showing the 2 high-resolution transects, the spatial limits of data for box modeling are depicted. Dots position some watercolumn monitoring stations that were sampled during 1994. Stations prefixed with ' $N$ ' surround the future offshore outfall, which is centered between Stns N20P and N16P about $15 \mathrm{~km}$ from Deer Island. Data from 2 lines of Bay stations (N01P to N10P and N04P to N07P, each representing about $10 \mathrm{~km}$ distance) were used to provide approximate concentrations for the future tidal source region for the Harbor isee 'Methods')
A recent study of Boston Harbor emphasized offshore export of the excessive nitrogen $(\mathrm{N})$ loading from land (>8000 $\mathrm{mmol} \mathrm{N} \mathrm{m}^{-2} \mathrm{yr}^{-1} ;-90 \%$ from sewage effluent), but ocean loading was not evaluated (Kelly 1997a). Quantification of ocean loading is needed to complete the present Harbor nutrient budget, but understanding of this process is also significant to the evaluation of conditions that will result from planned changes in effluent disposal. Direct discharge of sewage effluent by the Massachusetts Water Resources Authority (MWRA), the responsible agency, now occurs near Deer Island (north Harbor) and Nut Island (south Harbor) (Fig. 1). Diversion of all secondarily treated effluent now going into the Harbor is planned for late 1998, when a submarine pipe and seabed diffusers ( 30 to $35 \mathrm{~m}$ deep) will transport effluent about $15 \mathrm{~km}$ offshore into western Massachusetts Bay.

Using a variety of data from surveys through an annual cycle in 1994, combined with simple box modeling, I here assess rates of ocean loading of nutrients $\left(\mathrm{N}, \mathrm{P}, \mathrm{SiO}_{4}\right.$ ) and solids (total suspended solids, TSS) to Boston Harbor from the adjacent shelfwater region in western Massachusetts Bay. The exercise shows that ocean input of nutrients generally was greater than inputs from land during 1994. Predicted concentrations, made possible with estimates of total loading (from air and land, as well as from the ocean) and flushing time, agreed with observed Harbor concentrations, providing confidence in the budgets now available. Projections suggest that ocean loading will play an even larger role in future nutrient budgets. Consequently, projections of Harbor conditions during recovery from effluent diversion that neglect ocean loading will underestimate nutrient concentrations.

\section{METHODS}

Study area. Water in Boston Harbor at high tide covers $\sim 111 \mathrm{~km}^{2}$ (MHW) and at low tide about $\sim 95 \mathrm{~km}^{2}$ (MHW). The average depth is $-5.5 \mathrm{~m}$, with a mean tidal range $-2.7 \mathrm{~m}$. The Harbor is shallower, more turbid and more enriched in nutrients than the Bay. Tidal fronts regularly are evident several $\mathrm{km}$ outside the Harbor in Massachusetts Bay and a sharp drop in turbidity is common at this location (Kelly et al. 1995). For background on nutrient and production dynamics in the Harbor and the Bay, consult Kelly (1997a) and Kelly \& Doering (1997) and references therein.

Box modeling framework. Signell \& Butman (1992) used a high-resolution hydrodynamic model to describe flushing dynamics and identify tidal mixing zones at the 2 Harbor inlets (extending approximately to Stn F24, north Harbor, and Stn N10P, south Harbor; Fig. 1). The 


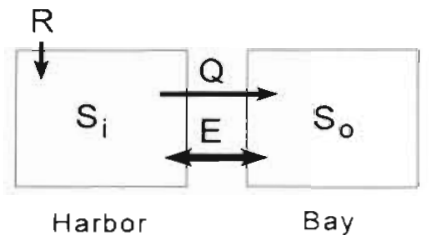

Fig. 2. The conceptual framework for box modeling. Model terms are described in the 'Methods'. Data were used to model exchange for the north and south Harbor transects shown in Fig. 1

simple modeling approach used here follows Officer (1980) and Officer \& Kester (1991) using a 2-D box model with gravitationally driven, advective flow and tidally driven, non-advective mixing (Fig. 2). Similar efforts have applied box models to other estuarine areas, including upper Narragansett Bay (RI, USA) (Doering et al. 1990). Briefly, the advective exchange $(Q)$ to the ocean (Massachusetts Bay) from Boston Harbor is driven by freshwater input $(R)$ to the Harbor. By conservation of volume to the Harbor, $R=Q$, so if one can measure $R$, part of the exchange with the ocean is determined. The tide brings ocean water into and out of the Harbor equally, so there is no net transfer of water, and the volume flooding into the Harbor at high tide $(E)$ equals the volume going out on the ebb tide $(E)$. Because incoming water mixes (to a degree) with the water in the Harbor, there is exchange and it is not the same water that simply moves back out even though equivalent volumes of water move in and out. Moreover, because of differences in salinity $(S)$ in the Harbor $\left(S_{i}\right)$ and the Bay $\left(S_{0}\right)$, there is transfer of salt even though there is no net water transfer. There is both a gross input (high tide) and a gross output (low tide), with the net exchange qualitatively suggested by which box has the higher $S$ (or concentration, $C$, for any substance). Salt is used as a conservative tracer to estimate the non-advective exchange $(E)$. By conservation of salt within the Harbor box, one can balance salt inputs and outputs as:

$Q S_{i}$ (advective output) $+E S_{1}$ (non-advective output) = $E S_{0}$ (non-advective input)

Rearranging terms, non-advective exchange can be estimated as:

$$
E=Q S_{\mathrm{i}} /\left(S_{\mathrm{o}}-S_{\mathrm{i}}\right)
$$

Assuming that each box (Fig 2) is well mixed and that the mean salinity of each box can be determined precisely, $E$ can be determined. The gross input (i.e. 'ocean loading') to the Harbor of any nutrient form can then be calculated as $(E) C_{0}$ and gross output as $(E+$ Q) $C_{\mathrm{i}}$.

In this study, separate box models were applied to both north and south Harbor regions (Fig. 1); these 2 regions somewhat separately communicate with the Bay through narrow inlets which restrict and regulate dynamics of exchange between the Harbor and the Bay (Signell \& Butman 1992). Harbor boxes for modeling (Fig. 2) represent the sampling transect from Stns F30B to F23P in the north Harbor and from Stn F31B to the Harbor-Bay boundary depicted in Fig. 1 (no station) in the south Harbor. The model term, $R$, estimates the volume passing through each Harbor box even though most of the river input is to the inner Harbor, landward from Stn F30B (Fig. 1). This is a reasonable simplification because river input to the inner Harbor eventually passes through the modeled region of the outer Harbor; moreover, effluent input, the major fraction of $R$, is discharged into or near the regions represented by the Harbor boxes. The Bay boxes being modeled represent the tidal source region from the 2 Harbor-Bay inlets eastward to Stns F24 and N10P of the north and south transects, respectively (Fig. 1). Box boundaries were determined from inspection of contoured sections that revealed the seaward extent of the tidal ebb-flood cycle (Kelly et al. 1995) and are spatially consistent with hydrodynamic modeling studies (Signell \& Butman 1992). The data for the model come from a dynamic, generally well-mixed Harbor region which directly receives the majority of the land and ocean loading, and the transects provide a representative sampling of conditions; for example, nutrient forms do not generally have notable spatial variability in the Harbor. It is recognized that lateral (off-transect) variability not assessed by the sampling design (cf. Kjerfve et al. 1981) would have more significance to solids and the resultant TSS budgets subsequently should be viewed as less certain than the nutrient budgets.

Besides exchange, the model concept also allows estimation of flushing time of a Harbor box. For this 'freshwater fraction method' (cf. Officer 1980, Pilson 1985), the volume of freshwater in the Harbor box $\left(V_{\mathrm{f}}\right)$ is equal to the total volume of the box $\left(V_{i}\right)$ times 1 minus the fractional salinity of the Harbor and Bay boxes $\left[1-\left(S_{\mathrm{i}} / S_{0}\right)\right]$. Knowing $V_{1}$, one can calculate flushing time ( $F T=$ 'residence time', see Pilson 1985) as:

$$
F T=V_{1} / R
$$

Surveys of the north Harbor in 1994 were spatially more extensive and temporally more frequent than for the south Harbor, and the available salinity data were consistently sufficient to enable exchange and flushing calculations for the north Harbor box (Fig. 1). High-resolution data for each survey of the north Harbor covered a $-6.5 \mathrm{~km}$ section which is deeper $(>10 \mathrm{~m})$ than most of the Harbor. For $V_{1}$, I assumed that transect data were representative of a $2000 \mathrm{~m}$ wide, $10 \mathrm{~m}$ deep sec- 
tion. $V_{\mathrm{f}}$ was then estimated using $S_{\mathrm{j}}$ and $S_{0}$, and $F T$ was calculated for each survey. Different assumptions for $V_{1}$ alter the estimate of FT, but do not alter the pattern of FT variability over surveys in 1994. Also, it can be shown that assumptions on the size of $V_{\mathrm{i}}$ do not affect predictions of (flushing-normalized) concentrations provided later, because of the direct relationship between $V_{1}$ and $F T$. $V_{\mathrm{i}}$ for the total Harbor varies from 4.30 to $7.19 \times 10^{8} \mathrm{~m}^{3}$ from mean low water (MLW) to mean high water (MHW), respectively (Signell \& Butman 1992, Signell pers comm.). Thus, the modeled outer Northern Harbor section represents $<12 \%$ of the total Harbor area and $\sim 18 \%$ of the total Harbor volume at high tide. Notably, the outer Northern Harbor is where the majority of the present effluent is discharged.

FT could vary with $R$, the freshwater input, with tides varying over the lunar cycle, winds, and other factors (e.g. Pilson 1985). For this study, the influence of $R$ and the tidal range (TR) on FT was examined using linear regression analyses. For each survey, $T R$ was estimated using a computer program, Tide1 (Micronautics Inc., Rockport, ME, USA), as detailed in survey reports (cf. Albro et al. 1993). Spring/neap variations are about $\pm 33 \%$ of the mean $T R(\sim 2.7 \mathrm{~m}$; Signell pers. comm.); the 9 surveys through 1994 spanned the spring/neap $T R$ cycle, ranging from -1.95 to $3.6 \mathrm{~m}$.

In summary, the data required for modeling are $R$, $S_{i}, S_{0}$ and $V_{1}$ as well as $C_{1}$ and $C_{0}$ for nutrient forms. Data sources and assumptions for $R, S_{\mathrm{i}}, S_{\mathrm{o}}, C_{\mathrm{i}}$, and $C_{\mathrm{o}}$ are provided below.

$\boldsymbol{R}$ (effluent and freshwater flow volumes): $R$ is available by combining data from studies of river and effluent flow. The MWRA measured daily flow rates of effluent volume for all of 1994, for both the Deer Island (north Harbor) and Nut Island (south Harbor) discharges (Fig. 1). Data provided to the author in $\mathrm{ft}^{3} \mathrm{~s}^{-1}$ were converted to $\mathrm{m}^{3} \mathrm{~s}^{-1}$

U.S. Geological Survey (USGS) river flow data (daily) at Waltham, MA, were provided for the major river flowing to Boston Harbor, the Charles River. The average flow for the $5 \mathrm{~d}$ period prior to each survey was used. Based on inspection of the data, river flow generally changed over slightly longer time scales; averaging for 2 to $7 \mathrm{~d}$ periods would not alter study conclusions, especially because freshwater flow was found to be small compared to tidal exchange. The USGS flow station on the Charles River is upstream of the point where the river actually enters the inner portion of the north Harbor. Reported flow was thus multiplied by the ratio of the total drainage area for the Charles to the drainage area feeding the river at the point of flow measurement $(=1.27$ ) (cf. Alber \& Chan (1994). Additionally, the flow from the Charles represents $61.5 \%$ of the total tributary flow to the north Harbor (Alber \& Chan 1994), so flows were divided by
0.615 to estimate total river flow to the north Harbor. Flow to the south Harbor is smaller, and was estimated as $5 \%$ of the flow to the north Harbor, following results of Alber \& Chan (1994). After corrections, the river flow data $\left(\mathrm{ft}^{3} \mathrm{~s}^{-1}\right)$ were converted to $\mathrm{m}^{3} \mathrm{~s}^{-1}$. Other freshwater sources summarized by Alber \& Chan (1994) are incidental $(\sim 10 \%$, most of which is direct precipitation, a sporadic input) and were not included in modeling.

$S_{\mathrm{i}}$ and $S_{\mathrm{o}}$ (water quality survey field data): Salinity was obtained from high-resolution (continuous) 'towyo' profiling using in situ sensors housed in a towfish (reported by Kelly et al. 1995, Kelly 1997a). The towfish was oscillated, with the vessel under way at 4 to 7 knots, from near-surface to near-bottom on transects through both Harbor inlets to a point near the middle of the future diffuser track in Massachusetts Bay. Only data for the track portions representing north and south Harbor and Bay (i.e. tidal source water) 'boxes' were used here (Fig 1). Dual-track (north and south inlet) surveys, with each track repeated near high and low tides, were conducted on 8 surveys. One additional special survey (June 1994) covered only the north Harbor-Bay transect, which was repeatedly sampled 6 times within one $12 \mathrm{~h}$ tidal cycle. This study makes use of in situ data for salinity (from conductivity, Seabird SBE-9, in PSU) and beam attenuation (of red light, SeaTech $25 \mathrm{~cm}$ pathlength, in $\mathrm{m}^{-1}$ ). High-resolution data were summarized as $2 \mathrm{~s}$ bins, resolving about 5 to $6 \mathrm{~m}$ horizontally and $<1 \mathrm{~m}$ vertically along the track.

For both the north ( 9 surveys) and south ( 8 surveys) inlets, the 2-box model and Eq. (1) were used to estimate $E$, non-advective exchange from tidal mixing. For each inlet and survey, t-tests assuming unequal variance (Cochran method, SAS 1988) were used to confirm if $S_{i}$ and $S_{0}$ were different; testing was performed using all $2 \mathrm{~s}$ bin-averaged data for each Harbor versus Bay 'box.' The differences were very small $(0.2$ to 0.7 PSU), but the large number of sample points (typically $n=1000$ to 1500 in each box) allowed powerful discrimination of mean differences. The only situation for which $S_{\mathrm{i}}$ and $S_{0}$ were not different at the $99 \%$ confidence level (but still at the $95 \%$ level) was for the south inlet on survey W9409 (Table 1); similar results were obtained with a non-parametric test (KruskalWallis; SAS 1988). In this case, inspection of the survey track revealed that the second transit did not extend all the way to Stn F31B and poorly characterized the south Harbor; thus, calculations for W9409 for the south Harbor are suspect (Table 1). For survey W9412, a finding of $S_{0}<S_{i}$ (by 0.2 PSU) in the south Harbor was also due to a shortened transect; in this case, exchange was not determined (Table 1).

$C_{\mathrm{i}}$ and $C_{\mathrm{o}}$ (hydrocast/bottle sampling and high-resolution measurements): $C_{1}$ and $C_{0}$ were obtained by standard hydrocast sampling done within days of the 
high-resolution surveys. Nutrient and TSS measurements have been described previously (Albro et al. 1993, Kelly 1997a). Nutrient forms generally measured and of interest in this study were ammonium $\left(\mathrm{NH}_{4}\right)$, nitrate + nitrite $\left(\mathrm{NO}_{3}+\mathrm{NO}_{2}\right)$, DIN $\left(\mathrm{NH}_{4}+\mathrm{NO}_{3}+\mathrm{NO}_{2}\right)$, total nitrogen $(\mathrm{TN}=\mathrm{DIN}+$ particulate $\mathrm{N}+$ dissolved organic N), phosphate $\left(\mathrm{PO}_{4}\right)$, and silicate $\left(\mathrm{SiO}_{4}\right)$. Sampling stations to characterize $C_{1}$ included $F 30 B$ and F23P in the north Harbor and F31B in the south Harbor. Massachusetts Bay stations to characterize $C_{0}$ lie within the tidal mixing zone: F24 (north) and F25 and N10P (south) (Fig. 1). Measurements were not available for all nutrient forms at all surveys (e.g. TN was only measured on 4 surveys). Moreover, for some surveys, concentrations were extrapolated from salinitynutrient relationships (cf. Kelly 1997a) based on data for the suite of Massachusetts Bay stations in Fig. $1 ;$ an additional MWRA database for nutrients in the Harbor was used to confirm reasonableness of $C_{\mathrm{i}}$ and $C_{0}$ estimates where possible. Table 2 lists the concentrations by box $\left(C_{1}, C_{0}\right)$ and transect (north, south) that were used in calculations.

Transmissometer readings were related to suspended particles by comparing paired measurements of total suspended solids (TSS, $\mathrm{mg} \mathrm{l}^{-1}$ ) on filtered water from hydrocasts with in situ beam attenuation (BA). Using all data in 1994 for stations in the Harbor or Bay box regions (Fig. 1), a significant linear regression was found that enabled prediction of TSS from attenuation readings: $\mathrm{TSS}=1.51( \pm 0.13) \mathrm{BA}-0.42( \pm 0.27)$, with $\mathrm{R}^{2}=$ $0.84, \mathrm{n}=28$. This relation enabled extensive readings of beam attenuation to be used to estimate ocean exchanges of TSS.
Calculation of Harbor-Bay exchange. Ocean loading (the gross input, or $E C_{0}$ ) from the Bay was calculated for nutrients and TSS for each survey, by combining the data of Tables 1 \& 2. Results were then tabulated to provide annual rates for different forms. The most extensive data are for beam attenuation and, by proxy, TSS. Annual gross output was also calculated, as $(E+Q)\left(C_{i}\right)$. Because $R$ (and thus $Q$ ) was minor, the tidal input volume $(E)$ was nearly equal to the total volume output $(E+Q)$. For the north Harbor, which has the greater river and effluent flow, the ratio of $E /(E+Q)$ averaged $\sim 98 \%$ for the surveys; for the south Harbor, the ratio was $>99 \%$. Consequently, differences between estimates of gross ocean inputs and outputs are more due to differences in concentrations observed inside and outside the Harbor than to differences (and uncertainties) in flows.

Additional budget terms. Hunt et al. (1995) provided annual effluent discharge rates for $\mathrm{N}, \mathrm{P}$, and $\mathrm{SiO}_{4}$ for 1994. To obtain an estimate of riverine loading for 1994, I modified the annual riverine loading estimate of Alber \& Chan (1994), multiplying it by the ratio of freshwater flow in 1994 to the long-term average used by Alber \& Chan (1994). Effluent and riverine loading estimates were then summed.

Summary budgets (Fig. 3) present results of ocean exchange calculations in the context of land sources (above) and with respect to some important removal or recycling processes within the Harbor (e.g. burial, denitrification, benthic fluxes). Derivation of these internal' process rates was provided for N by Kelly (1997a); additional citations and assumptions are given in Fig. 3.

Table 1. Data and model results for $E$ (non-advective exchange) for the north and south Harbor transects. $R$ : freshwater input; $Q$ : advective exchange; $S_{\mathrm{i}}$ : Harbor salinity; $S_{\mathrm{o}}$ : Bay salinity; nd: not determined

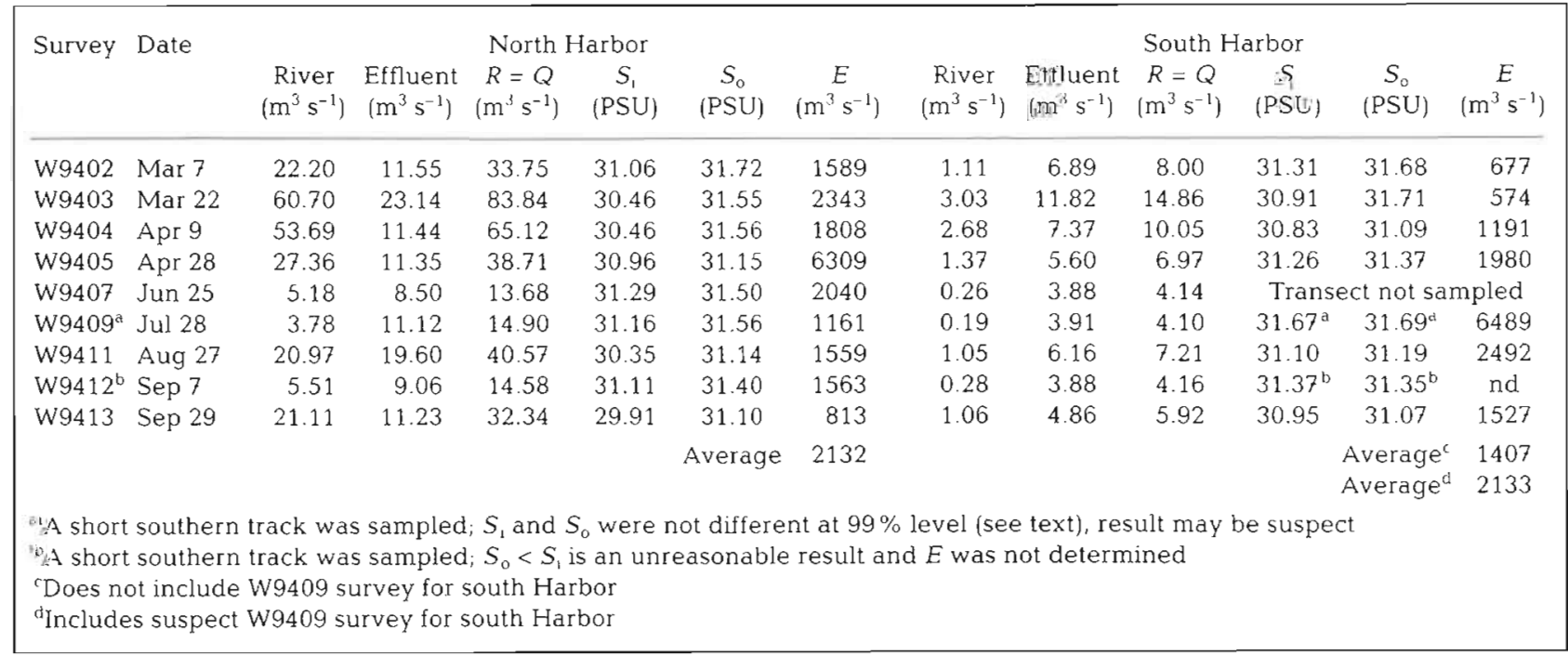


Table 2. Bay $\left(C_{0}\right)$ and Harbor $\left(C_{1}\right)$ concentration data used in calculating Harbor-Bay exchange. BA: beam attenuation from transmissometer readings; nd: not determined

\begin{tabular}{|c|c|c|c|c|c|c|c|c|c|c|c|c|c|}
\hline \multirow[t]{2}{*}{ Survey } & \multirow[t]{2}{*}{ Transect } & \multicolumn{6}{|c|}{ Bay $C_{0}$ (to calculate ocean loading) } & \multicolumn{6}{|c|}{ Harbor $C_{1}$ (to calculate Harbor output) } \\
\hline & & $\begin{array}{c}\mathrm{BA}^{\mathrm{d}} \\
\left(\mathrm{m}^{-1}\right)\end{array}$ & $\begin{array}{l}\mathrm{NH}_{4} \\
(\mu \mathrm{M})\end{array}$ & $\begin{array}{l}\text { DIN } \\
(\mu \mathrm{M})\end{array}$ & $\begin{array}{c}\mathrm{TN} \\
(\mu \mathrm{M})\end{array}$ & $\begin{array}{c}\mathrm{PO}_{4} \\
(\mu \mathrm{M})\end{array}$ & $\begin{array}{l}\mathrm{SiO}_{4} \\
(\mu \mathrm{M})\end{array}$ & $\begin{array}{l}\mathrm{BA}^{\mathrm{a}} \\
\left(\mathrm{m}^{-1}\right)\end{array}$ & $\begin{array}{c}\mathrm{NH}_{4} \\
(\mu \mathrm{M})\end{array}$ & $\begin{array}{l}\text { DIN } \\
(\mu \mathrm{M})\end{array}$ & $\begin{array}{c}\mathrm{TN} \\
(\mu \mathrm{M})\end{array}$ & $\begin{array}{l}\mathrm{PO}_{4} \\
(\mu \mathrm{M})\end{array}$ & $\begin{array}{l}\mathrm{SiO}_{4} \\
(\mu \mathrm{M})\end{array}$ \\
\hline \multirow[t]{2}{*}{ W9402 } & North & 2.23 & 3 & 10.5 & 20 & 0.8 & 8 & 2.34 & 4 & 14 & 28.5 & 08 & 12 \\
\hline & South & 1.89 & 2 & 9.5 & 18 & 0.8 & 8 & 1.78 & 3.5 & 12.5 & 19 & 1 & 9.5 \\
\hline \multirow[t]{2}{*}{ W9403 } & North & 1.23 & 1. & 2 & nd & 0.3 & 1 & 1.61 & nd & nd & nd & nd & nd \\
\hline & South & 1.07 & 0.75 & 1.75 & nd & 0.3 & 0.75 & 1.32 & nd & nd & nd & nd & nd \\
\hline \multirow[t]{2}{*}{ W9404 } & North & 0.85 & 2 & 3 & 16 & 0.3 & 1.5 & 1.29 & 3 & 4.5 & 25 & 0.3 & 3 \\
\hline & South & 1.11 & 1. & 2 & 14 & 0.25 & 1 & 1.30 & 2.5 & 3.25 & 18 & 0.25 & 1.4 \\
\hline \multirow{2}{*}{ W9405 } & North & 1.53 & 1.5 & 3 & nd & 0.5 & 2.75 & 1.84 & nd & nd & 13 & 0.5 & nd \\
\hline & South & 1.46 & 1.5 & 3 & nd & 0.5 & 2.75 & 2.00 & nd & nd & 11 & 0.8 & nd \\
\hline \multirow[t]{2}{*}{ W9407 } & North & 1.55 & 1.5 & 2 & 14 & 0.7 & 1.5 & 2.15 & 2.25 & 2.6 & 17.5 & 0.6 & 1.5 \\
\hline & South & nd & nd & nd & nd & nd & nd & nd & 2 & 3 & 14.5 & 0.8 & 2.5 \\
\hline \multirow[t]{2}{*}{ W9409 } & North & 2.04 & 5 & 6 & nd & 1 & 4.5 & 3.26 & 2.1 & nd & 11 & 0.7 & nd \\
\hline & South & 1.50 & 5 & 6 & nd & 1 & 4.5 & 1.64 & 1.4 & nd & 10.5 & 0.55 & nd \\
\hline \multirow[t]{2}{*}{ W9411 } & North & 1.51 & 7 & 11 & 21. & 1.1 & 6 & 2.07 & 10 & 15 & 26 & 1.3 & 8 \\
\hline & South & 1.78 & 4 & 7 & 16 & 1 & 5 & 1.90 & 11 & 16 & 24 & 1.3 & 7 \\
\hline \multirow[t]{2}{*}{ W9412 } & North & 2.13 & 6 & 8 & nd & 1 & 3 & 2.66 & 2.25 & nd & 20 & 1.5 & nd \\
\hline & South & nd & 6 & 8 & nd & 1 & 3 & nd & nd & nd & 2.1 & 1.5 & nd \\
\hline \multirow[t]{2}{*}{ W9413 } & North & 1.94 & 2 & 3.5 & nd & 0.5 & 2.75 & 2.06 & 15 & 20.5 & 29.7 & 1.7 & nd \\
\hline & South & 1.86 & 2 & 3.5 & nd & 0.5 & 2.75 & 2.06 & 18 & 20.5 & 29.7 & 1.7 & nd \\
\hline
\end{tabular}

\section{RESULTS}

\section{Tidal exchange rates for the Harbor}

Modeled estimates of $E$, the volume exchanged during tidal mixing, made using Eq. (1) are provided in Table 1. For 9 surveys which sampled the north inlet, $E$ ranged from $813 \mathrm{~m}^{3} \mathrm{~s}^{-1}$ on September 29 (near neap tide conditions) to $6309 \mathrm{~m}^{3} \mathrm{~s}^{-1}$ on April 28 (a spring tide), with an average of $2132 \mathrm{~m}^{3} \mathrm{~s}^{-1}$. E for the southern inlet averaged 1407 to $2133 \mathrm{~m}^{3} \mathrm{~s}^{-1}$, the range depending on whether or not the survey with the less reliable E estimate (W9409) was included (Table 1).

Combining results for the entire harbor, the estimate of $E$ represented an annual volume exchange of 1.12 to $1.34 \times 10^{11} \mathrm{~m}^{3}$, or an average of $\sim 3500$ to $4300 \mathrm{~m}^{3} \mathrm{~s}^{-1}$. This range represents from 54 to $65 \%$ of the volume of the average tidal prism, a result that is consistent with physical modeling results (Signell \& Butman 1992, Signell pers. comm.). It is noted that survey estimates include an unquantified influence of wind, which can affect E (Signell \& Butman 1992). In comparison to tidal exchange, the average freshwater flow to the whole Harbor for all daily measurements of 1994 was $37 \mathrm{~m}^{3} \mathrm{~s}^{-1}$. with $20 \mathrm{~m}^{3} \mathrm{~s}^{-1}$ from rivers and $17 \mathrm{~m}^{3} \mathrm{~s}^{-1}$ from effluent Thus, the non-advective tidal volume exchange was on the order of 100 times the advected-volume throughput (Q) driven by land drainage (cf. Kelly 1997b).

\section{Ocean loading in the context of Harbor nutrient budgets}

Harbor-Bay exchanges are compared with all other terms of the Harbor budget in Fig. 3 and Table 3. Ocean loading is the major input of nutrients and suspended solids to Boston Harbor. There is more than 2 times the input of total nitrogen (TN), and slightly more DIN, from tidal input as there is from land sources (Fig. 3a). Total phosphorus (TP) in ocean loading was not determined, but $\mathrm{PO}_{4}$ from the ocean, as well as $\mathrm{SiO}_{4}$, appears to be about 2 or more times the input from land (Fig. 3b, c). The difference between ocean and land loading appears profound for TSS, where the estimate of effluent and river sources is only $0.4 \times 10^{5} \mathrm{t}$ $\mathrm{yr}^{-1}$, compared to 2.3 to $2.8 \times 10^{5} \mathrm{t} \mathrm{yr}^{-1}$ from tidal input (Fig. 3d).

The Harbor's nutrient budgets (circa 1994) are more constrained now that total inputs are estimated (cf. Kelly 1997a) and an approximate balance is noted where all forms are included (cf. nitrogen, Fig. 3a, Table 3). For example, total TN inputs minus internal losses were similar to gross outputs. Actually, total TN inputs to the entire Harbor were slightly less than gross outputs (Table 3), which could suggest that benthic fluxes of DIN (Fig. 3a) are rapidly exported, but uncertainties in input/output estimates from $E$ modeling preclude making strong statements on that topic. 

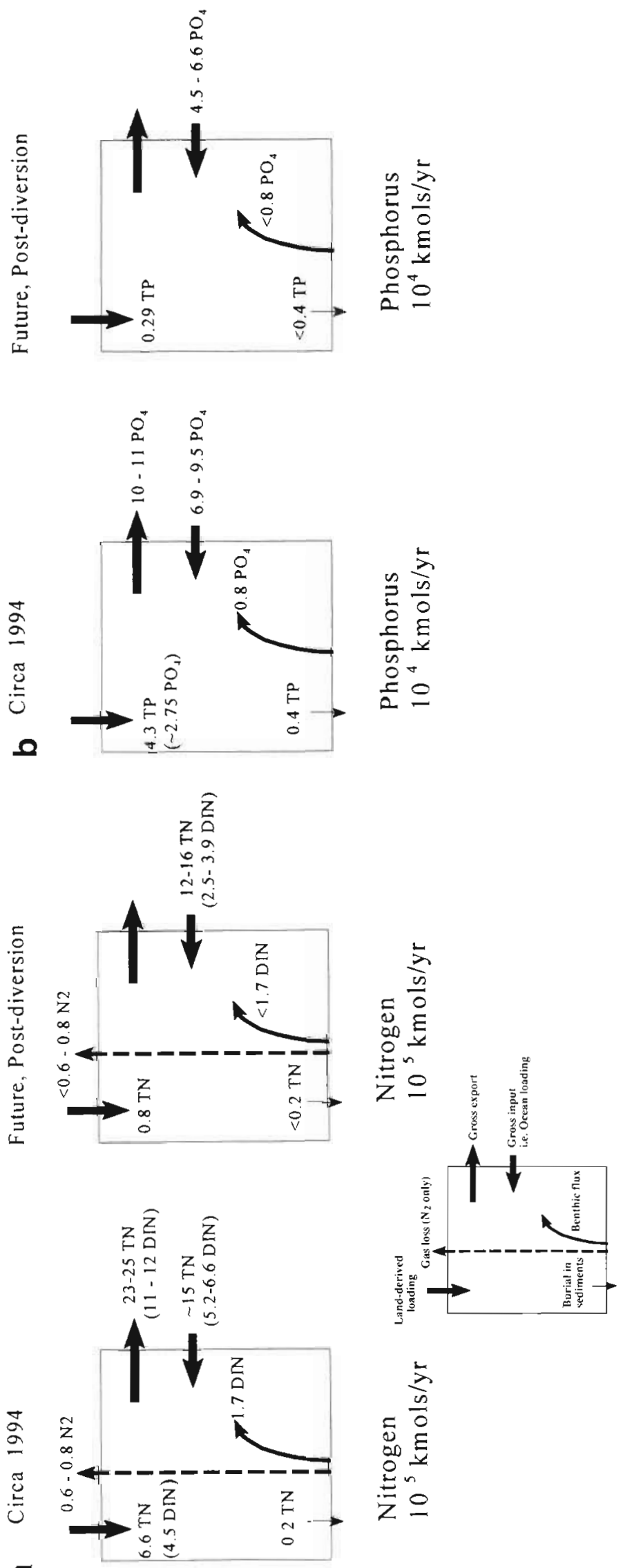

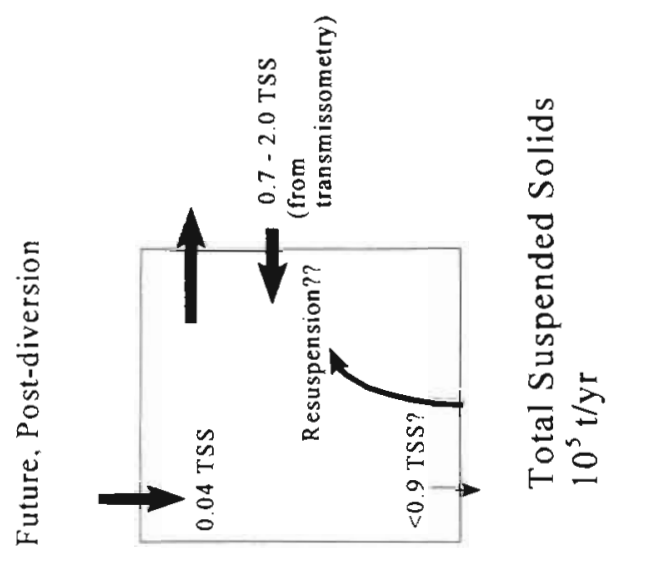

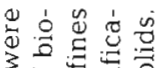

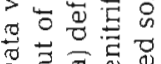

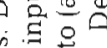

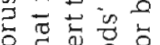

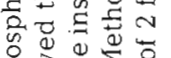

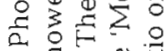

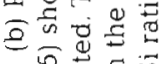

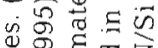

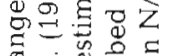

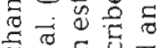

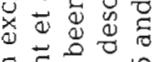

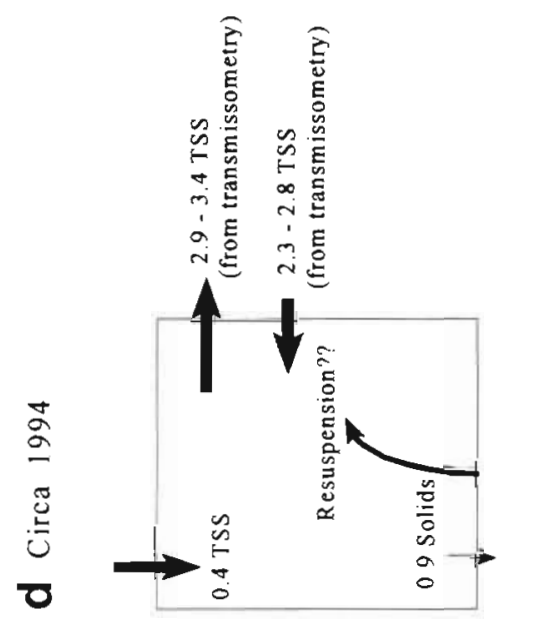

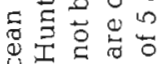

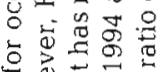

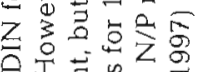

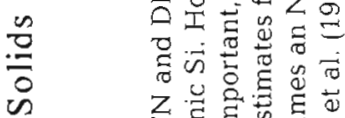
is Z Z

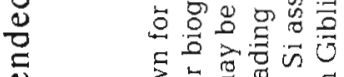

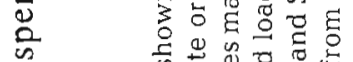
北

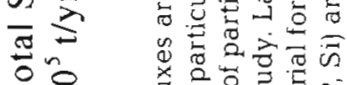
응

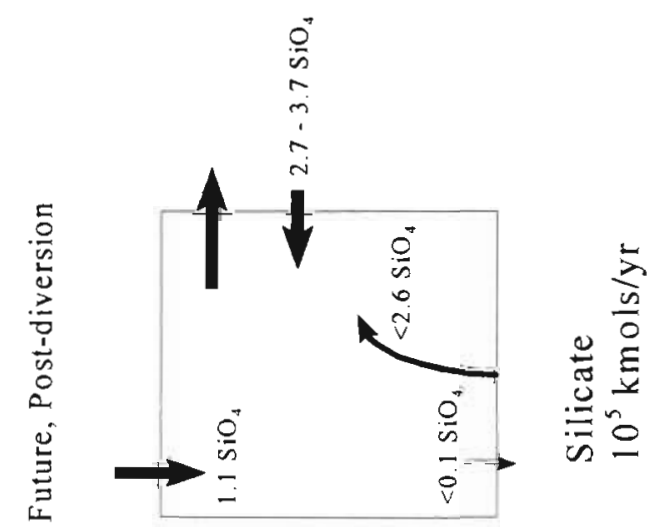

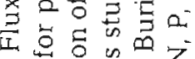

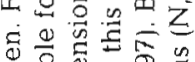

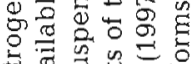

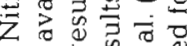

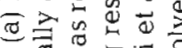

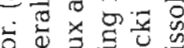

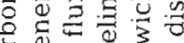
훙.

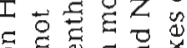

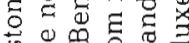

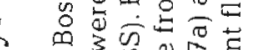
홍 क

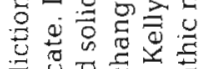

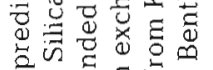
可

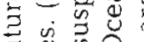

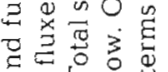

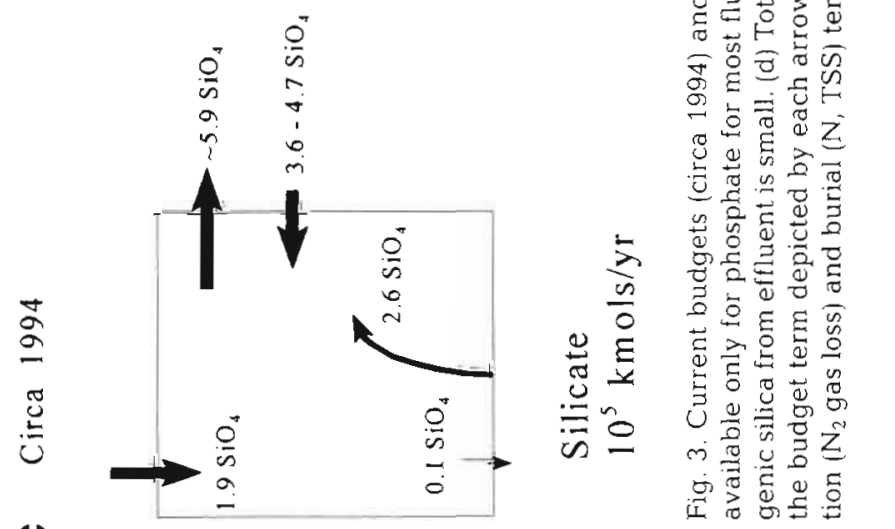


Table 3. Annual nitrogen budget for Boston Harbor and intensively sampled north Harbor region, circa 1994. Units are $10^{5}{\mathrm{kmol} \mathrm{yr}^{-1}}^{-1}$

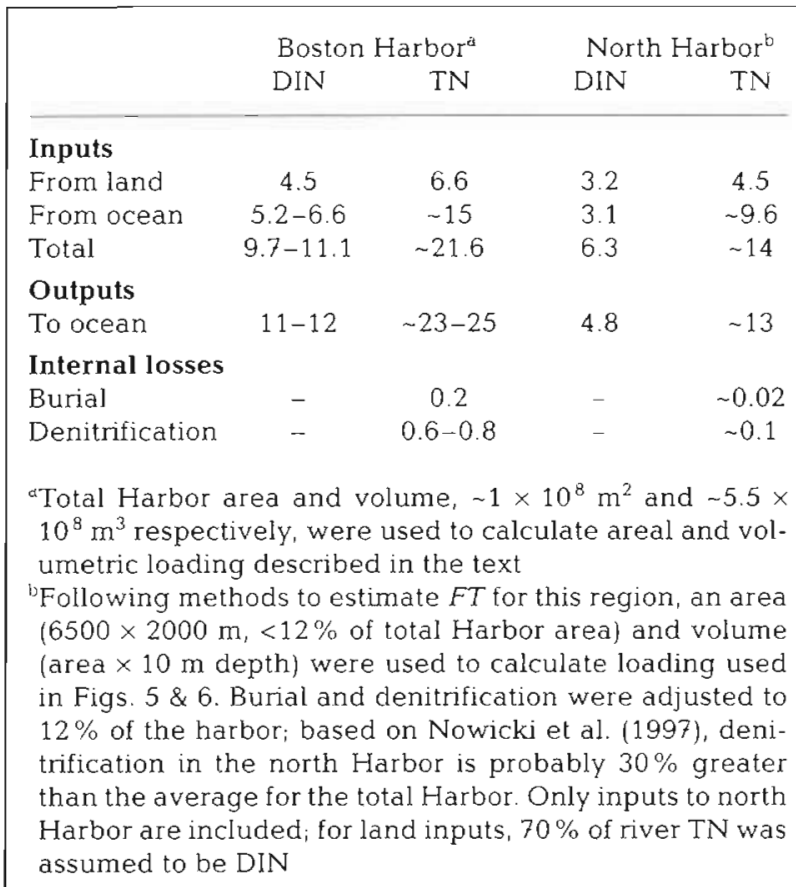

Uncertainties also preclude precisely estimating net export (difference between total input and gross output) in the TN budget. Nonetheless, as previously described (Kelly 1997a), the role of internal $N$ removal processes is small and it remains clear that most of the land loading of $\mathrm{N}$ to the Harbor passes offshore. For $\mathrm{PO}_{4}$ and $\mathrm{SiO}_{4}$ (Fig. 3b, c), approximate inputoutput balances are apparent and efficient export of land loading may also occur, but organic forms should be included in all fluxes to obtain a full accounting

The TSS budget (Fig. 3d) also shows an approximate input-output balance, but it too has a major difference compared with nutrient budgets. The measured solids input from land is not large enough to support estimated sediment burial. The ocean input of solids is very large in comparison to the land loading and would seem to offer an additional source to support burial; accumulation of marine clays in Boston Harbor is a notion previously raised by Knebel (1992). However, the burial estimate has large uncertainty (Kelly 1997a) and the role of resuspension (seasonal and episodic) is poorly known; moreover, in contrast to being a net import from the ocean, the modeling suggests that the Harbor was a net exporter of TSS to the Bay in 1994. Net export is suggested by small differences in ranges for ocean inputs and outputs in Fig. 3d, but the strongest case for TSS export is provided by 2 comparisons of spatial and temporal trends in beam attenuation. First, intensive tidal study of the north Harbor in June (W9407, Table 1) showed that beam attenuation in the Harbor dropped with the flooding tide as water from the Bay with lower beam attenuation entered the Harbor. Second, within-Harbor beam attenuation was virtually always higher than beam attenuation in the Bay just outside each Harbor inlet (cf. Table 2), as confirmed by statistical comparison testing for Harbor and Bay boxes (similar to that described for salinity in the 'Methods').

\section{Nutrient budgets and further modeling: an example using the north Harbor}

If one has an estimate of total loading, as well as knowledge of the flushing time of a well-mixed box, an average concentration can be predicted. If internal losses to sediment processes (burial, denitrification) are known, they can also be accounted for, as in our case. The north Harbor region data set was sufficient to conduct the following brief exercise.

Flushing time (FT) for the north Harbor

Fig. 4 summarizes $F T$ calculated for the 9 relevant surveys in 1994 (Table 1 ). The sampled region has rapid flushing, with $F T$ averaging 0.92 d. Variation

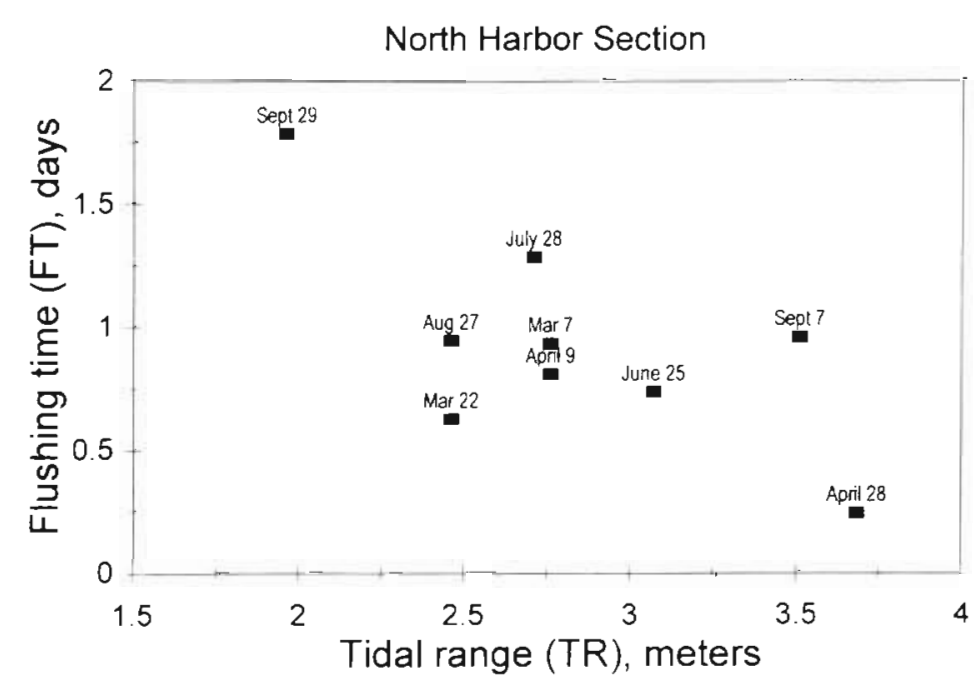

Fig. 4. Calculated flushing time of the north Harbor section as a function of tidal range, for 9 high-resolution transect surveys during 1994 
with the tidal range $(T R)$ was indicated. A predictive linear regression was obtained which explained almost $50 \%$ of the FT variation: $F T=2.49( \pm 0.62)-0.56( \pm 0.22) T R$, with $R^{2}=0.49$ and where parentheses indicate standard error of the parameter coefficients. The March 22 survey had relatively low FT for its $T R$; this survey occurred during some of the highest spring runoff and high freshwater input $(R)$ (Table 1). Recognizing the possible influence of freshwater input, $R$ was included with $T R$ in a stepwise multiple regression. $R$ was selected after $T R$ as the second variable in the model and the overall model fit was improved $\left(R^{2}=0.83\right)$, resulting in the following formulation:

$$
\begin{aligned}
F T= & 3.35( \pm 0.47)-0.72( \pm 0.14) T R- \\
& 0.011( \pm 0.003) R
\end{aligned}
$$

FT was thus higher (i.e. a slower flushing rate) at neap tides and during low freshwater input, but the range was small across the surveys, from 0.24 to $1.77 \mathrm{~d}$. Using the range of values of $T R$ (1.95 to 3.67 , mean $2.8 \mathrm{~m}$ ) and $R$ (14 to 84 , mean $\left.37.5 \mathrm{~m}^{3} \mathrm{~s}^{-1}\right)$ a general dominance of $T R$ over $R$ in controlling FT was indicated. From Eq. (3), high springtime runoff $\left(84 \mathrm{~m}^{3} \mathrm{~s}^{-1}\right)$ is predicted to be slightly less effective at flushing the outer north Harbor than neap $(1.95 \mathrm{~m})$ tides.

\section{Concentrations for the north Harbor: predicted and observed in 1994}

A budget for nitrogen for the north Harbor is provided along with that of the whole Harbor in Table 3. Fig. 5 uses the total DIN and TN input to the outer north Harbor from Table 3 ; similarly, $\mathrm{SiO}_{4}, \mathrm{PO}_{4}$, and TSS inputs to the north Harbor were calculated. The $x$ axis shows annual areal loading ( $\left.\mathrm{mmol} \mathrm{m} \mathrm{mr}^{-2}\right)$, which is a common reporting unit. One can convert to volumetric loading ( $\mu$ mol $\left.\mathrm{l}^{-1} \mathrm{yr}^{-1}\right)$, knowing the average depth. Dividing volumetric loading by the number of

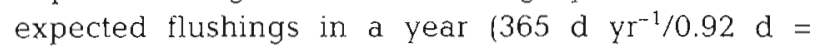
$397 \mathrm{yr}^{-1}$ ) yields an estimate of the average concentration in the north Harbor expected for the residence

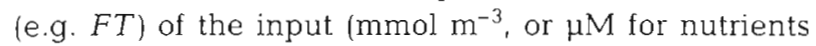
and $\mathrm{mg} \mathrm{l}^{-1}$ for TSS). In Fig. 5, the resultant predicted concentrations from the 1994 budget have been reduced to account for internal losses based on Fig. 3, adjusted for the smaller north Harbor region as indicated in Table 3. Internal losses were very small; even in the case of $N$, with both denitrification and sediment burial (Table 3 ), the loss was only $0.29 \mu \mathrm{M}$. For com- parison, average annual concentrations for 1994 ( $\mathrm{n}=$ 24 to 78 , depending on the form) were determined for the 2 hydrocast stations at the edges of the defined north Harbor box (Fig. 1). Fig. 5 shows a highly favorable comparison of predicted and observed concentrations of all forms, adding confidence in the budgets and modeling estimates obtained for ocean exchange.

\section{DISCUSSION}

\section{Significance of ocean loading}

The principal finding of this study is that the input of nutrients and solids to Boston Harbor is the dominant fraction of the total input. This is the case even though there is a very large mass of nutrients entering with the sewage effluent discharged to the Boston Harbor. For comparison, the DIN load from the metropolis surrounding New York Harbor, from land sources only, has been estimated as $\sim 32000 \mathrm{mmol} \mathrm{m} \mathrm{m}^{-2} \mathrm{yr}^{-1}$ (Nixon \& Pilson 1983). The land sources to Boston Harbor bring $\sim 4500$ to $5500 \mathrm{mmal} \mathrm{DIN} \mathrm{m} \mathrm{ms}^{-1}$, but the total input of DIN is on the order of 10000 to $11000 \mathrm{mmol} \mathrm{m}^{-2} \mathrm{yr}^{-1}$. For the smaller area of the outer north Harbor section which was examined extensively in this study, the total DIN input is almost $50000 \mathrm{mmol} \mathrm{m}^{-2} \mathrm{yr}^{-1}$ and the total $\mathrm{TN}$ input is in excess of $100000 \mathrm{mmol} \mathrm{m} \mathrm{yr}^{-1}$ (Fig. 5). 
This study is one of the first to provide direct estimates of ocean loading for a major estuary and in doing so achieve a semblance of budget balance or 'closure' (cf. Nixon et al. 1995). In the northeast USA. where substantial tidal ranges are the norm, the nutrient economies of many systems will have a similarly significant role for tidal inputs. Tidal actions and ocean loading are especially important at locations with low river flow which lack the level of land-based anthropogenic source loads of Boston (Kelly 1997b). Understanding of many northeast estuaries requires recognition of the role of estuary-ocean exchange. Accordingly, the traditional 'watershed as source' focus that dominates coastal management approaches must be extended to include stronger characterization of the connection between shallow inshore waters and their adjacent coastal shelfwaters.

This study's ocean exchange and predictive modeling undoubtedly was aided because (1) there was high-resolution characterization of salinity achieved by the sampling technique, with small mean salinity differences detectable, and (2) physical (tidal) processes are rapid and controlling influences. Physical results were consistent with recent hydrodynamical studies (Signell \& Butman 1992, Signel]. et al. 1996) which also indicate (1) a short $F T$, (2) a strong influence of the lunar tide cycle, and (3) that only a fraction of the tidal prism that advects into the Harbor actually mixes with Harbor water. In principle, the basic approach used here should also work in more poorly flushed systems, including backwater segments of Boston Harbor.

\section{Total inputs and prediction of in situ conditions}

This study illustrates the importance of knowing total (and gross ocean) input rather than, for example, land-based inputs and net ocean exchange by tides. For example, calculations of in situ concentrations (normalized for flushing) like those given in the above results would yield predictions that were about half or less of observed values for DIN and TN in the north Harbor (cf. Table 3, Fig. 5) if gross ocean loading were neglected. The tidal input water that carries most of the gross material input also drives the residence time of the Harbor. In theory, any material that comes in and stays resident within a flushing time can have ecological influence so, in short, there are relevant contexts for needing to know both gross and net estuary-shelf exchanges. Biological processes in colder seasons are not fast enough to modify concentrations set by physical mixing and flushing in Boston Harbor; strong export of inorganic nutrients results (Kelly 1997a). During summer, river flow tends to be reduced
(Table 1) so flushing times lengthen, albeit slightly. The seasonal temperature rise boosts biogeochemical processes, which become fast enough to act on, modify, and be influenced by nutrient inputs; export of organic forms then occurs in summer (Kelly 1997a). Such observations on dynamics, among other considerations, suggest that ocean loading may have its strongest ecological influence during summer (cf. Nixon et al. 1995)

Successful predictive modeling (e.g. Fig. 5) indicates that in situ concentrations integrate and reflect total inputs and flushing. Where internal biogeochemical losses are small (or at least quantifiable) and especially if flushing is at least roughly estimated, in situ conditions can provide a strong sense of total inputs, as well as trophic status (see also Kelly $1997 \mathrm{a}$, b). A solid characterization of water quality conditions, supplemented with simple modeling, thus can add fundamental insight on estuaries and embayments. While this suggestion should be somewhat obvious, there has been enormous research and management effort over the past few decades to develop coastal nutrient budgets (this study included), some at the expense of better monitoring of in situ conditions of the systems of interest.

\section{Ocean loading and Harbor recovery after diversion of sewage effluent}

Future budget projections (Fig. 3) allow exploration of the role of ocean loading when the present effluent discharge is diverted from the Harbor. At that time, Boston Harbor will better typify conditions of less developed embayments along the New England coast, although it will be in a stage of recovery for some period. The topic of recovery formed the impetus for this paper and frames a final discussion point.

To achieve budget projections, the present effluent contribution to land sources was removed, though the river inputs were assumed to be the same as 1994 . Future $E$ values were assumed to be the same as the present since they are driven by tides. However, concentrations in the ocean source water will be different in the future and an issue is to determine an appropriate concentration for the future tidal source region.

Concentrations presently in the Bay region that acts as tidal source water are supported in part by the discharge into the Harbor, so that some of that tidally exported material returns to the water with succeeding flood tides (e.g. Signell \& Butman 1992). In a sense, the present 'ocean loading' term, defined by Harbor-Bay boundary definitions, is like regeneration from bottom sediments - each process returns nutrients back to 
waters resident within the Harbor. The hydrodynamic modeling of Signell et al. (1996) suggests that future Bay floodwater input concentrations may be slightly lower than at present. Their results suggest that present dilution of effluent at Stns N01P to N10P is about the same as will occur in the future for the region from Stn F24 to F23P (Bay 'box' modeled for 1994), when effluent is released at the seabed between Stns N20P and N16P (Fig. 1). Thus I used concentrations from this set of stations measured in 1994 (Kelly 1997a) as input to the ocean loading calculations. For this set, the average annual concentrations were used: $3.39 \mu \mathrm{M}$ DIN, $14.5 \mu \mathrm{M} \mathrm{TN}, 0.54 \mu \mathrm{M} \mathrm{PO}_{4}, 3 \mu \mathrm{M} \mathrm{SiO}{ }_{4}$, and $1.37 \mathrm{mg} \mathrm{l}^{-1}$ for TSS (generally slightly lower than concentrations used in 1994 modeling; cf. Table 2). To provide a range, I also examined results with lower concentration data from the photic zone (to $30 \mathrm{~m}$ ) at stations $10.5 \mathrm{~km}$ further seaward (N04P to N07P) that would closely approximate a Bay 'background' without effluent (Kelly 1997a). For this set, average annual concentrations were $2.55 \mu \mathrm{M}$ DIN, $13.6 \mu \mathrm{M}$ TN, $0.44 \mu \mathrm{M} \mathrm{PO}_{4}$, $2.67 \mu \mathrm{M} \mathrm{SiO}_{4}$, and $0.6 \mathrm{mg} \mathrm{l}^{-1}$ for TSS. At a minimum, the exercise indicates the qualitative significance of ocean loading in the future; the greatest difference in the 2 sets is for TSS since the seaward set is far from inshore turbidity.

The principal finding of the projected budgets is that ocean loading, though diminished, will dwarf land sources more than it does at present. This is uniformly suggested for nutrients (N, P, Si) and TSS in Fig. 3, which shows the range in ocean loading using the 2 concentration sets. Using projected total inputs as again normalized by FT, future average concentrations for the north Harbor were calculated (Fig. 6). For this example, the higher of the future ocean loading ranges was used. Removal of effluent freshwater input was factored into the projection with respect to its influence on FT, using Eq. (3). The effect was minor as FT is projected to increase by $-10 \%$ on average. Relative to 1994 , predicted concentrations (i.e. post effluent diversion to the Bay) show a decrease of about 20\% for TN and 50\% for DIN (Fig. 6). A coupled water-quality/hydrodynamic model of the entire Bay and Harbor region similarly predicted a $-50 \%$ drop in DIN in the Harbor after effluent diversion (Hydroqual \& Normandeau 1995, Signell et al. 1996). That model was considerably more complex than the simple box model used in this study, but was also based on mass balance considerations which implicitly include exchanges between the Bay and Harbor. An important final observation on projections apparent from this study is that if ocean loading were neglected, one would expect the future north Harbor DIN concentration to be $<1$ rather than the $\sim 5 \mu \mathrm{M}$ predicted in Fig. 6.

Total $\mathrm{P}$ budgets could not be produced with existing data, but projections (Fig. 6) for $\mathrm{PO}_{4}$ and $\mathrm{SiO}_{4}$ concentrations suggest a future decrease that is less than that for DIN, reflecting that the present effluent discharge is DIN-rich compared to the relatively DIN-poor Bay water. Consequently, the ratios of N/P and N/Si for the inorganic forms may decline slightly after diversion (Fig. 6). Projected changes are not large but are uncertain. Nonetheless, the direction of change suggests greater $\mathrm{N}$ limitation with proportionately more $\mathrm{Si}$, a trend that in principle would tend to favor diatoms over other phytoplankton species (cf. Officer \& Ryther 1980, Doering et al. 1989).

The inshore-offshore gradient in TSS is sharper than for nutrients (see above), so the projected range of ocean loading is broader and more uncertain, but TSS concentrations will likely decrease (Fig. 3). The actual change may be critical to ecological recovery of the Harbor, because particle concentrations affect light and nutrient uptake (e.g. Kelly \& Doering 1997) as well as pelagic-benthic coupling in shallow coastal areas (e.g. Santschi 1985, Doering et al. 1986). Interestingly though, beam attenuation (and TSS) presently tends to

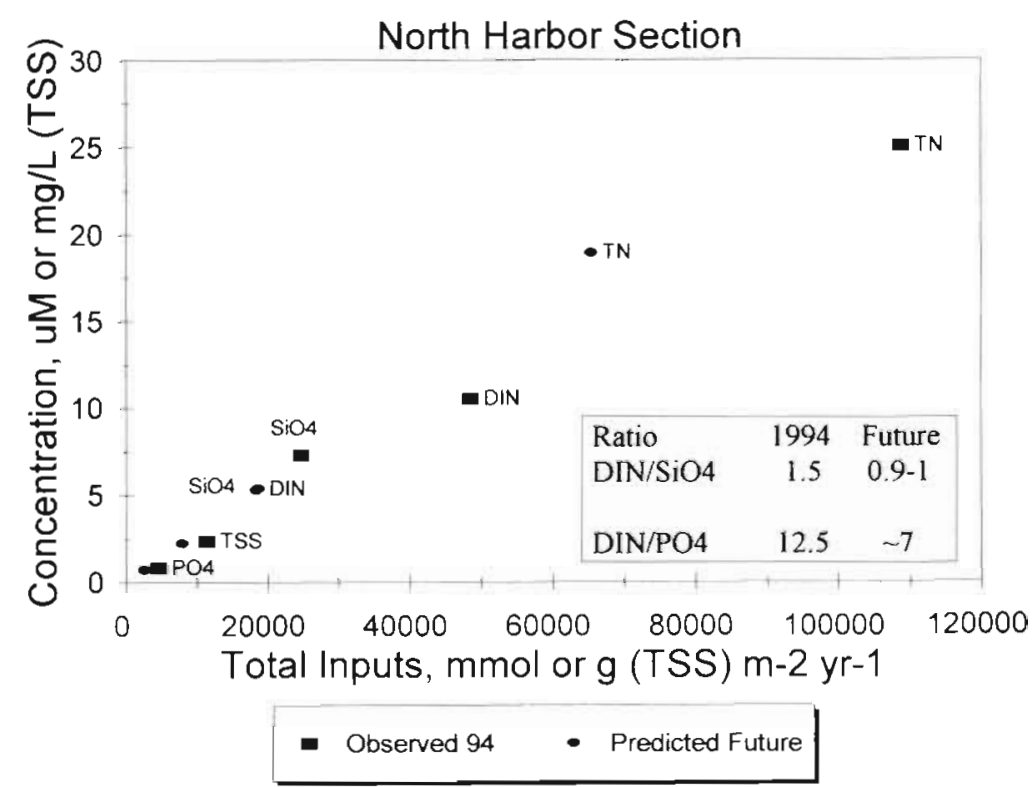

Fig. 6. Comparison of observed and predicted (future) nutrient concentrations based on estimated future total loading (north Harbor section only), after normalization of volumetric-based loading for flushing time (adjusted for removal of effluent flow). The text describes the basis for estimating the ocean loading portion of the future total loading 
be higher in the Harbor in summer than in winter (see Table 2; also D. Taylor pers. comm.). Biological activity increases during summer and processes like bioturbation, resuspension, and benthic filter-feeding can all affect TSS. In short, TSS seasonality in the Harbor may strongly relate to internal dynamics as much as or more than to loading. Despite uncertainties regarding the future interplay of biology, particles, light, and nutrients, summer will be a critical time with respect to Harbor recovery. With effluent flow removed, the remaining low summertime freshwater inputs (rivers are usually $<10 \mathrm{~m}^{3} \mathrm{~s}^{-1}$; cf. Table 1) will further enhance the role of tidal exchange $\left(-4000 \mathrm{~m}^{3} \mathrm{~s}^{-1}\right)$ in providing TSS and nutrients. Ocean loading (and internal processes) will have dominant roles in dictating water quality and fueling summertime Harbor metabolism, bringing nutrients within the residence time established by tides at a time when biota is most capable of utilizing them.

\section{CONCLUSIONS}

Box modeling indicated a large amount of ocean loading to Boston Harbor, and furthermore allowed construction of one of the first (for the Harbor or elsewhere) complete input-output budgets for nutrients $\left(\mathrm{N}_{1} \mathrm{P}, \mathrm{SiO}_{4}\right)$ and suspended solids. Ocean loading is the dominant flux in the Harbor budget for nutrients and suspended solids. After sewage effluent diversion, we can expect ocean loading to decrease slightly for most elements; concomitant with the effluent diversion and change in ocean loading, concentrations in the Harbor will drop. Even so, the dominance of tidal inputs on the Harbor nutrient budget will be more pronounced than at present and the influence of ocean loading on the ecology of a recovering Harbor may be most profound in summer.

Acknowledgements. The MWRA provided funding for this study and Jim Blake at ENSR Consulting facilitated the project. Cited technical reports are available from the Environmental Quality Department, MWRA, Boston, Massachusetts 02129, USA. I thank Rich Signell (USGS, Woods Hole), Eric Adams (MIT), Carl Pawlowski (MWRA), David Taylor (MWRA) and Doug Hersh (MWRA) for providing data and counsel. Carl Albro (Battelle) provided outputs of the tide range program and Peter Doering (South Florida Water Management District) pointed out some references and gave me insight on box-modeling approaches. Mike Connor, Mike Mickelson, Ken Keay, Wendy Leo and David Taylor (MWRA) were open to the suggestion that ocean loading might be important to Harbor recovery; I thank Mike MickeIson, Ken Keay, and David Taylor as well as anonymous reviewers for helpful comments on the manuscript. Conclusions are solely the perspective of the author and do not necessarily reflect the opinion or perspective of the MWRA.

\section{LITERATURE CITED}

Alber M, Chan A (1994) Sources of contaminants to Boston Harbor revised loading estimates. MWRA Environ Quality Dep Tech Rep Ser No. 94-1. Massachusetts Water Resources Authority, Boston

Albro C, Kelly JR, Hennessey J, Doering P, Turner J (1993) Combined work/quality assurance plan for baseline water quality monitoring: 1993-1994. MWRA Environ Quality Dep Tech Rep Ser No. ms-14. Massachusetts Water Resources Authority, Boston

Doering PH, Oviatt CA, Beatty LL, Banzon VF, Rice R, Kelly SP, Sullivan BK, Frithsen JB (1989) Structure and function in a model coastal ecosystem: silicon, the benthos and eutrophication. Mar Ecol Prog Ser 52:287-299

Doering PH, Oviatt CA, Kelly JR (1986) The effects of the filter feeding clam Mercenaria mercenaria on carbon cycling in experimental marine mesocosms. J Mar Res 44 : 839-861

Doering PH, Oviatt CA, Pilson MEQ (1990) Control of nutrient concentrations in the Seekonk-Providence River region of Narragansett Bay, Rhode Island. Estuaries 13(4):418-430

Giblin AE, Hopkinson CS, Tucker J (1997) Benthic metabolism and nutrient cycling in Boston Harbor, Massachusetts. Estuaries 20(2):346-364

Hunt CD, West DE, Peven CS (1995) Deer Island effluent. characterization and pilot treatment plant studies: June 1993-November 1994. MWRA Environ Quality Dep Tech Rep Ser No. 95-7. Massachusetts Water Resources Authority, Boston

Hydroqual and Normandeau (1995) A water quality model for Massachusetts and Cape Cod Bays: calibration of the Bays Eutrophication Model (BEM). MWRA Environ Quality Dept Tech Rep Ser No. 95-8. Massachusetts Water Resources Authority, Boston

Kelly JR (1997a) Nitrogen flow and the interaction of Boston. Harbor with Massachusetts Bay. Estuaries 20(2):365-380

Kelly JR (1997b) Nutrients and human-induced change in the Gulf of Maine - 'One, if by land, and two, if by sea.' In: Wallace GT, Braasch EF (eds) Proc Gulf of Maine Ecosystem Dynamics, A Scientific Symposium and Workshop. RARGOM Report 97-1. Regional Association for Research on the Gulf of Maine, Hanover, p 169-181

Kelly JR, Albro CS, Geyer WR (1995) High-resolution mapping studies of water quality in Boston Harbor and Massachusetts Bay during 1994. MWRA Environ Quality Dept Tech Rep Ser No. 96-1. Massachusetts Water Resources Authority, Boston

Kelly JR, Doering PD (1997) Monitoring and modeling primary production in coastal waters: studies in Massachusetts Bay 1992-1994. Mar Ecol Prog Ser 148:155-168

Kjerfve B, Stevenson LH, Proehl JA, Chrzanowski H, Kitchens WM (1981) Estimation of material fluxes in an estuarine cross section: a critical analysis of spatial measurement density and errors. Limnol Oceanogr 26(2):325-335

Knebel. HJ (1992) Sedimentary environments within a glaciated estuarine-inner shelf system: Boston Harbor and Massachusetts Bay. Mar Geol 110:7-30

Nixon SW (1997) Prehistoric nutrient inputs and productivity in Narragansett Bay. Estuaries 20(2):253-261

Nixon SW, Granger SL, Nowicki BL (1995) An assessment of the annual mass balance of carbon, nitrogen, and phosphorus in Narragansett Bay. Biogeochemistry 31:15-61

Nixon SW, Pilson MEQ (1983) Nitrogen in estuarine and coastal marine ecosystems. In: Carpenter EJ, Capone DG (eds) Nitrogen in the marine environment. Academic Press, New York, p 565-648 
Nowicki BL, Kelly JR, Requintina E, Van Keuren D (1997) Nitrogen losses through sediment denitrification in Boston Harbor and Massachusetts Bay. Estuaries 20:626-639

Officer CB (1980) Box models revisited. In: Hamilton P, Macdonald $\mathrm{KB}$ (eds) Estuarine and wetland processes with emphasis on modeling. Plenum Press, New York p 65-114

Officer CB, Kester DR (1991) On estimating the non-advective tidal exchanges and advective gravitational circulation in an estuary. Estuar Coast Shelf Sci 32:99-103

Officer CB, Ryther JH (1980) The possible importance of silicon in marine eutrophication. Mar Ecol Prog Ser 3:83-91

Pilson MEQ (1985) On the residence time of water in Narra-

Editorial responsibility: Otto Kinne (Editor),

Oldendorf/Luhe, Germany gansett Bay. Estuaries 8(1):2-14

Santschi PH (1985) The MERL mesocosm approach for studying sediment-water interactions and ecotoxicology. Environ Technol Lett 6:335-350

SAS (1988) SAS procedures guide, release 6.03 edn. SAS Institute, Inc, Cary, NC

Signell RP, Butman B (1992) Modeling tidal exchange and dispersion in Boston Harbor. J Geophys Res 97:15191-15606

Signell RP, Jenter HL, Blumberg AF (1996) Circulation and effluent dilution modeling in Massachusetts Bay: model implementation, verification, and results. U.S. Geological Survery Open File Rep 96-015

Submitted: January 21, 1998; Accepted: July 13, 1998 Proofs received from author(s): October 21, 1998 